Elsevier required licence: (c) <2019>. This manuscript version is made available under the CC-BY-NC-ND 4.0 license http://creativecommons.org/licenses/by-nc-nd/4.0/

The definitive publisher version is available online at https://doi.org/10.1016/j.colegn.2019.10.001 


\section{"Conquering the Great Divide: rural mothers of children with chronic health conditions accessing specialist medical care for their children"}

Sally Bristow ${ }^{1}$, RN, RM, PhD Candidate, Debra Jackson ${ }^{2}, \mathrm{RN}, \mathrm{PhD}$ Professor of Nursing, Tamara Power ${ }^{2}{ }^{2} \mathrm{RN}, \mathrm{PhD}$ Senior Research

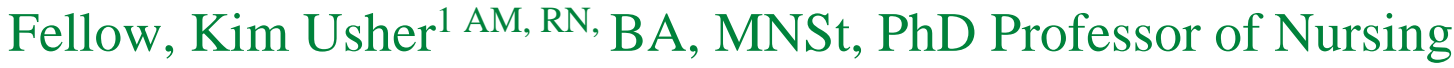

${ }^{1}$ School of Health, University of New England, Armidale NSW

${ }^{2}$ Faculty of Health, University of Technology Sydney (UTS), Australia

Corresponding author:

Dr Tamara Power, Faculty of Health, University of Technology Sydney (UTS), Australia, Australia.

Email: Tamara.Power@uts.edu.au 


\section{Abstract}

Background: Globally, the number of children with chronic health conditions (CHCs) is increasing and mothers are mostly responsible for their care.

Aim: Few studies have focused on rural mothers and their experiences of sourcing health care for their children who have CHCs. The purpose of this study was to explore these experiences.

Method: Using a phenomenological approach, semi-structured interviews were conducted in early 2018. The Consolidated criteria for Reporting Qualitative research (COREQ) guidelines were followed. Sixteen rural mothers were interviewed regarding their experiences of accessing health care to provide optimal management of their children's CHC.

Findings: Thematic analysis of resulting data revealed the overarching theme 'Conquering the great divide'. From this overarching theme, four themes emerged. This paper focuses on the first theme, 'Heading to the big smoke: access'.

Discussion: Rural mothers felt challenged accessing health care for their children in the major cities whilst also maintaining routine family life back home.

Conclusion: Understanding these rural women's experiences could assist health care professionals to develop strategies to facilitate rural mothers accessing services for their children with a CHC.

\section{Summary of Relevance}

\section{Problem or Issue}

- The impact caring for a child with a chronic health condition in rural Australia has on mothers and their families.

- Understanding the challenges rural mother face in providing appropriate care for their child with chronic health condition

\section{What is Already Known}

- The number of children with chronic health condition is increasing globally and accessing appropriate health care for these children is essential for their growth, development and health outcomes. 
- Rural residents have limited or no access to specialist health resources locally and accessing health services in metropolitan areas places significant challenges for patients and their families/carers, contributing to the burden of care

\section{What this Paper Adds}

- This paper provides evidence that rural mothers experience significant challenges in caring for their child with a $\mathrm{CHC}$, including early diagnoses, referral processes, accessing care outside their community and communication.

- This paper identifies the need for health care professional to support rural mothers in caring for their child with a $\mathrm{CHC}$ to ensure they have access to appropriate health-care, resources and services they require to provide optimal care.

\section{Keywords}

- Chronic health condition, Rural, Mother, Distance, Travel

\section{Introduction}

Globally, chronic health conditions are a major contributor to the burden of disease. The number of children with chronic health conditions is increasing (Berntsson et al., 2007; Leeman et al., 2016). According to the Australian Institute of Health and Welfare (Health, 2012a) two in five (1.5million) Australian children aged 0-14 years have a least one chronic health condition (Health, 2012b). Individuals living in rural and remote communities tend to access health services less than those living in metropolitan and regional areas, which may contribute to the poorer health outcomes for rural people (Health, 2012a). Children living with $\mathrm{CHCs}$ require ongoing care and support for optimum management of their conditions.

Mothers assume the bulk of the responsibility for managing their children's health and development, seeking health care and services for their children and making care decisions (Jackson and Mannix, 2004; Swallow et al., 2012). In Australia, in 2015, 88\% of primary carers for children identified as being female and aged between 25 and 44 years (Australian Bureau of Statistics (ABS, 2015). Mothers that provide care and support to their children with a $\mathrm{CHC}$ endure additional strains on their everyday lives (Bristow et al., 2018). 
Previous studies have explored families' experiences of caring for children who have a CHC (Bessette Gorlin et al., 2016; Barlow and Ellard, 2006; Cousino and Hazen, 2013; Bristow et al., 2018; Nygård and Clancy, 2018) but few studies have focused on rural mother's experiences (Farmer et al., 2005; Sodi and Kgopa, 2016; Lauver, 2010). Understanding mothers' experiences may assist health care providers to become more aware of the impact rurality has on accessing the services required to provide optimal care for children with a CHC. Knowing the enablers and barriers rural mothers face when accessing care for their child could assist service providers in planning new models of care and developing services and resources that are responsive to these women's caregiving requirements.

Australia is one of the least densely populated countries in the world with over seventy percent of Australians living in major cities (ABS, 2016). In this study, participants lived in the Australian state of New South Wales (NSW). NSW is the most populated Australian state with most of the population living in major cities along the coastline. The Great Dividing Range, a mountain range that stretches across the east coast of Australia, creates a geographical divide separating the coastal and inland areas of NSW.

\section{Background}

A recent literature review revealed that distance creates challenges for rural mothers in accessing health care services for their children who have a CHC (Bristow et al., 2018). Diagnosis of a child with a $\mathrm{CHC}$ is distressing for any mother; for rural mothers the distress is exacerbated because of distance from specialist medical staff and services - it is more of a challenge due to delays in diagnosis, difficulty navigating health care services from a distance, and finding the additional monetary and other resources needed to access these services for their child (Farmer et al., 2005; Skinner and Slifkin, 2007; Murphy et al., 2012). Australian and international studies have highlighted that there is a misdistribution of the health workforce in particular medical practitioners in relation to geographical location (Sen Gupta et al., 2018). This is evidenced in rural Australia with a shortage of medical practitioners both generalist and specialist alongside of this there are shortages of therapist who provide therapy services commonly to children with chronic conditions (Gallego et al., 2016; Gallego et al., 2017; Hussain and Tait, 2015). Alongside of this rural mothers had to learn to navigate complex health networks, medical systems and service providers located great distances from their home communities Furthermore, in order to meet their child's health care needs (Bristow et al., 2018).

NSW has three tertiary children's hospitals providing specialist health services, but all are based in two major coastal cities that lie east of the Great Dividing Range. Participants in this study lived up to $600 \mathrm{~km}$ away from these hospitals. The rural location of the mother was categorized using the Modified Monash Model (MMM). The MMM divides Australia into seven categories based on geographical 
remoteness and town size. This system incorporates the Australian Bureau of Statistics (ABS) remoteness classification system, the Australian Standard Geographical Classification -Remoteness Areas (ASGC-RA 2016), and road distance to access services. Data were collected from each of the participants describing distance from their local town, land size and access to services including schooling, employment and health care resources.

Previous research has largely focused on experiences of mothers in the context of a particular diagnoses such as autism, arthritis and cerebral palsy (Hoogsteen and Woodgate, 2013; Tong et al., 2013; Buran et al., 2009). Few studies have focused on the experiences of rural mothers of children with CHCs more generally. The focus of this article is the first theme 'Heading to the big smoke: access'. In this theme, rural mothers identified substantial real-world challenges they experienced when living in a rural location and travelling with their children to metropolitan areas to receive the necessary care and services they required for their child's health and well-being. Understanding rural mothers' experiences may enable rural and metropolitan health service personnel an opportunity to improve existing services and develop new strategies to support rural mothers in their vital role of caring.

\section{Method}

\section{Methodology}

van Manen's (1990) hermeneutic phenomenological approach was selected as the research methodology for this study as this approach allowed the researcher to explore rural mothers' experiences of caring for a child with a $\mathrm{CHC}$ in-depth. Phenomenology provided insight into the lived experience of rural mothers providing care for their children with chronic health conditions focusing on aspects of the mothers own experience as viewed and told by them (Flood, 2010). This methodological approach provided a systematic way to analyse and interpret the phenomenon as outlined in Table 2 (Van Manen, 1990; Van Manen, 2001).

\section{Ethical approval}

Ethical approval for this study was granted through the Human Research Ethics Committee of the XXX. All participants were provided with information regarding the study including a participant information sheet, consent form and ethics approval letter. Informed consent was secured prior to the interview. Pseudonyms have been used to ensure participant privacy.

\section{Procedure}

A recruitment postcard was developed and distributed through rural paediatricians, social media sites and rural women's networks including the Country Women's Association, the Department of Primary Industry Rural Women's Network, and rural radio. The postcard included details of the study and how 
women could contact the research team for further information. Mothers who were interested in participating contacted the lead researcher $(X X)$ through social media, phone or email and the information sheet and consent form were provided. When women made contact a return email or phone discussion determined if they met the inclusion criteria, which was being a rural-dwelling mother of a child with $\mathrm{CHC}$. Mothers of children with an imminent life-limiting condition such as cancer or with a child recently diagnosed with a $\mathrm{CHC}$ (last 12 months), were excluded from this study as the focus was on the long-term, everyday care requirements over time.

Mothers interviewed for this study identified as being the primary carer of a child with a CHC aged between 2-18 years, residing in a rural location. All participants from this study came from rural NSW with sixteen residing within or west of the Great Dividing Range resulting in the overarching theme 'Conquering the great divide'. Interviews were conducted in the mother's homes or other mutually convenient locations. Video and telephone conferencing were also offered. Semi-structured interview questions were used for data collection. Questions were open ended to allow participants the opportunity to provide a detailed description of their experience as recommended by van Manen (1990). Each interview lasted between 120-180 minutes. Interviews were audiotaped and transcribed verbatim. Interviews were conducted by the first author, herself a rural-dwelling mother of children with $\mathrm{CHC}$. Field notes were taken to record relevant contextual details and participants completed a 15-minute demographic form prior to the interview. The demographic form captured information such as size of the family, the child's chronic health conditions, service requirements including health care providers, time involved in care, distance, number and types of health care and resources required for care, family income and benefits and employment status. The initial question: "What is your experience as a rural mother caring for your child/children with a chronic health condition?" was followed by several semi-structured prompts as required. Sixteen women were recruited into the study. All were white, partnered women.

\section{Data analysis}

Transcripts were analysed alongside demographic data and field notes using van Manen's (1990, pp. 30-31) six-step research process for analysis outlined in Table 1. This enabled the research team to identify common understandings of the rural mothers' experiences caring for children with a $\mathrm{CHC}$. 


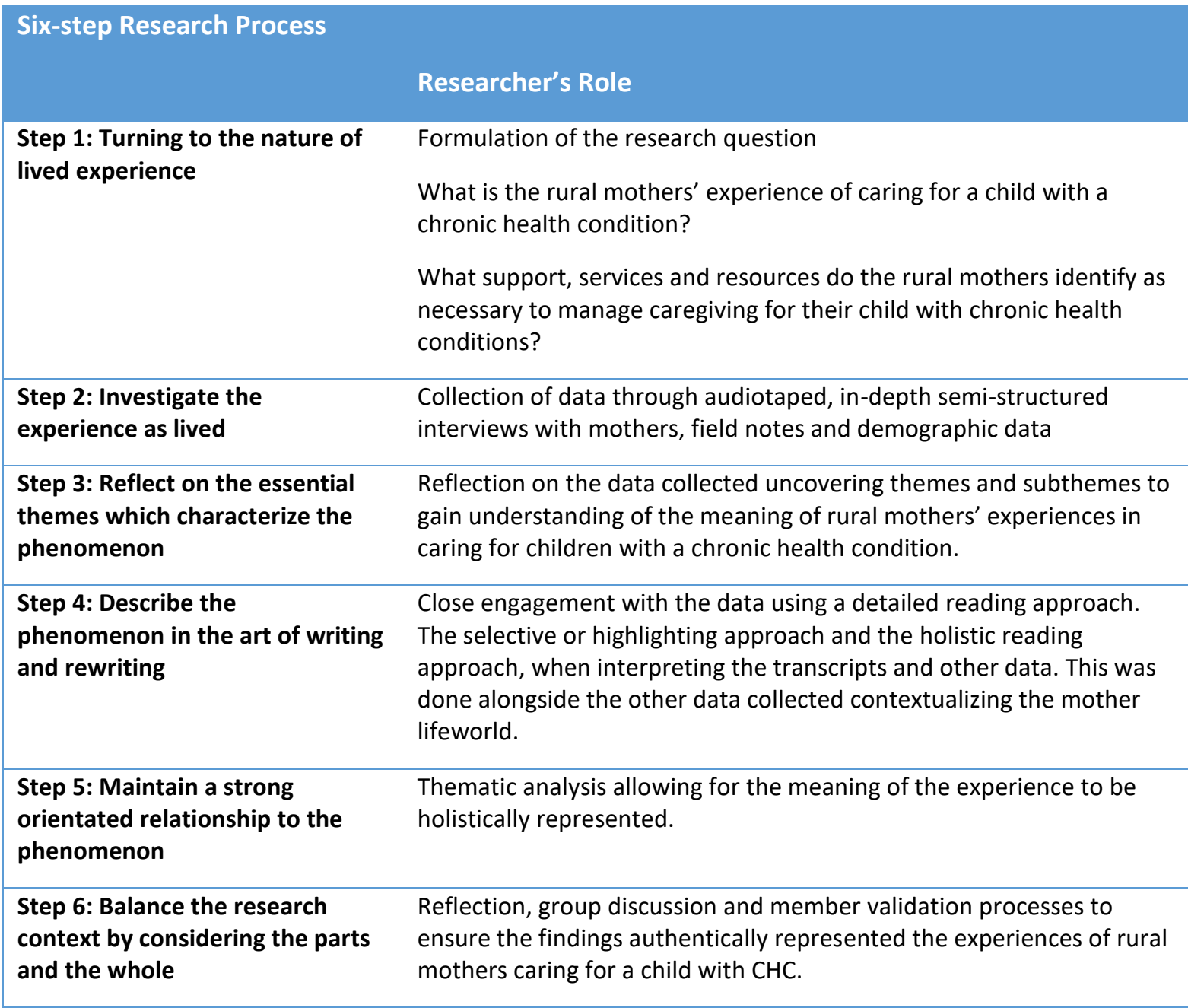

Following preliminary analysis, discussion amongst the team continued until the overarching theme, themes and sub-themes were refined and consensus was reached. The richness of the data and the commitment to fully honour and elucidate the experiences of the women necessitates reporting of each theme separately. Results are reported following the COREQ guidelines (Tong et al., 2007).

\section{Findings}

The mothers demographic details are provided in Table 2 including the rural location using the MMM.

Please note, all names are pseudonyms. 
Table 2: Participant demographics

\begin{tabular}{|c|c|c|c|c|c|c|c|c|c|c|}
\hline \multirow[t]{2}{*}{ Mother } & \multirow{2}{*}{$\begin{array}{l}\text { Rural } \\
\text { location }\end{array}$} & \multirow[t]{2}{*}{ Child 1} & \multirow[t]{2}{*}{ Child 2} & \multirow{2}{*}{$\begin{array}{c}\text { Distance } \\
\text { to local } \\
\text { town }\end{array}$} & \multirow{2}{*}{$\begin{array}{c}\text { Distance } \\
\text { to } \\
\text { specialist }\end{array}$} & \multirow{2}{*}{$\begin{array}{c}\text { Specialist } \\
\text { involved } \\
\text { in care (n) }\end{array}$} & \multicolumn{4}{|c|}{ Type Specialist Clinician } \\
\hline & & & & & & & $\mathrm{Dr}$ & $\mathrm{N}$ & $\mathrm{AH}$ & Other \\
\hline Rachel & MMM4 & Luke & & in town & $500 \mathrm{~km}$ & $5-10$ & 6 & 1 & 3 & \\
\hline Christine & MMM3 & Dahlia & $\begin{array}{l}\text { Anastasi } \\
\text { a }\end{array}$ & $5 \mathrm{~km}$ & $520 \mathrm{~km}$ & $11-15$ & 9 & 1 & 3 & \\
\hline Lisa & MMM5 & Calvin & $\begin{array}{l}\text { Jude } \\
\text { (twin2) }\end{array}$ & $50 \mathrm{~km}$ & $600 \mathrm{~km}$ & 4 & 2 & 1 & 1 & \\
\hline Natasha & MMM5 & Sabrina & & $50 \mathrm{~km}$ & $500 \mathrm{~km}$ & $5-10$ & 4 & 1 & 1 & 2 \\
\hline Michelle & MMM4 & Edwina & & $10 \mathrm{~km}$ & $550 \mathrm{~km}$ & $11-15$ & 3 & & 3 & 5 \\
\hline Rebecca & MMM3 & Holly & Cooper & in town & $600 \mathrm{~km}$ & $5-10$ & 4 & & 2 & 5 \\
\hline Sarah & MMM5 & Gareth & Hayden & $50 \mathrm{~km}$ & $600 \mathrm{~km}$ & 4 & 4 & & & \\
\hline $\begin{array}{l}\text { Samanth } \\
\text { a }\end{array}$ & MMM5 & Frank & & in town & $500 \mathrm{~km}$ & $5-10$ & 3 & & 3 & 1 \\
\hline Melissa & MMM6 & Jonty & $\begin{array}{l}\text { Brent } \\
\text { (twin2) }\end{array}$ & $70 \mathrm{~km}$ & $500 \mathrm{~km}$ & $5-10$ & 1 & & 5 & 1 \\
\hline Renee & MMM5 & Sasha & & $40 \mathrm{~km}$ & $600 \mathrm{~km}$ & $5-10$ & 2 & & 5 & \\
\hline Karen & MMM5 & Caleb & Henry & $60 \mathrm{~km}$ & $600 \mathrm{~km}$ & $5-10$ & 4 & & 2 & 3 \\
\hline Jodie & MMM5 & Casey & & $45 \mathrm{~km}$ & $500 \mathrm{~km}$ & 4 & 2 & & 1 & 1 \\
\hline Kelly & MMM4 & Nate & Cleo & in town & $500 \mathrm{~km}$ & $11-15$ & 7 & 1 & 1 & \\
\hline Vanessa & MMM5 & Nina & & $35 \mathrm{~km}$ & $500 \mathrm{~km}$ & $11-15$ & 6 & 1 & 2 & 4 \\
\hline Helen & MMM6 & Ezra & Ashur & $100 \mathrm{~km}$ & $430 \mathrm{~km}$ & $5-10$ & 4 & & 4 & 2 \\
\hline Melinda & MMM5 & Millie & Flynn & $30 \mathrm{~km}$ & $600 \mathrm{~km}$ & $16+$ & 8 & 1 & 4 & 4 \\
\hline $\begin{array}{l}\text { Legend } \\
\text { MMM } 3 \\
\text { MMM } 4 \\
\text { MMM } 5 \\
\text { MMM } 6 \\
\text { MMM } 7\end{array}$ & \multicolumn{6}{|c|}{$\begin{array}{l}\text { large rural population } 1500-50000 ; \\
\text { medium rural population } 5000-15000 \text {; } \\
\text { small rural population }<5000 ; \\
\text { remote } \\
\text { very remote } \\
\text { (Department of Health, 2019). }\end{array}$} & \multicolumn{4}{|c|}{$\begin{array}{l}\text { Legend } \\
\mathrm{Dr} \text { - Medical Doctor } \\
\mathrm{N} \text { - Nurse } \\
\mathrm{AH} \text { - Allied health } \\
\mathrm{O} \text { Other }\end{array}$} \\
\hline
\end{tabular}

Mothers in this study reported facing multiple challenges in accessing health care services for their children. More than half the women interviewed had two children with a $\mathrm{CHC}$, not necessarily the same $\mathrm{CHC}$, many of the children had multiple $\mathrm{CHC}$ and seven participants had children with rare $\mathrm{CHCs}$. The challenges of caring were complicated by distance and travel as specialised health care services are generally centralised within cities. For these mothers, resourcing care involved negotiating with numerous local clinicians. However, the local health providers had lengthy waiting lists and were the gatekeepers for accessing referrals to specialist care and services, creating frustrations and compounding delays. The overarching theme, themes and subthemes are indicated in table 3 , with the theme explored in this shaded in table 3. Accessing specialist services from a distance created circumstances are reflected in the three sub-themes 'Enduring the wait', 'Prepared for the Journey' and, 'Strangers in the city'. 
Table 3: Themes and subthemes (focus of this current paper is shaded)

\begin{tabular}{|c|c|c|}
\hline \multirow{2}{*}{ Overarching theme } & Themes & Subthemes \\
\hline \multirow{3}{*}{$\begin{array}{c}\text { Conquering the } \\
\text { Great Divide }\end{array}$} & Heading to the Big Smoke: access & $\begin{array}{c}\text { Enduring the wait } \\
\text { Prepared for the journey } \\
\text { Strangers in the city }\end{array}$ \\
\cline { 2 - 2 } & Lost in the Borderlands: isolation & \\
\cline { 2 - 2 } & Country Communities: support & \\
\cline { 2 - 2 } & Surmounting the Terrain: acceptance & \\
\hline
\end{tabular}

\section{Enduring the wait}

Participants initially began seeking help through their general practitioner (GP). Within Australia the GP is often the first point of contact for individuals with health concerns and it is through the GP that further investigations and care such as referral to a specialist practitioner are mediated. Within rural Australia there is a shortage of GP's and many rural towns are reliant on locums to provide this service.

"living in a rural area it's hard to get in to a GP. ..... so you end up with whoever you can get in to at the time.... and that's not good for continuity of care" (Christine)

The mothers discussed the importance of working with the GP in order to access the necessary investigations that would eventually lead to a diagnosis. However, the first step towards getting a diagnosis; of engaging the GP and getting the necessary referrals were sometimes protracted and mothers reported they felt they were not always listened to.

.... So it took a long time for me to be able to get someone to recognise that Caleb had a problem. And so that took a fair bit of hammering and talking and trying to find someone who would listen to the fact that I thought there was problems (Karen).

Once the mother negotiated the referral, they then began seeking specialist health care which resulted in further delays. Once the necessary referrals were obtained, there could be quite a wait for the actual appointment and even once a specialist was seen, the mothers sometimes still felt their concerns were trivialised and that they were not being listened to. After quite a lengthy delay in seeing the first specialist, Rachel had to go back to square one and request seeing another paediatrician, as she felt that the initial specialist did not take her seriously and she felt dismissed and as though she was being labelled as an over-protective mother. 
Something's not right, I was just told that I was an overprotective, too-educated parent and that there was nothing wrong. He (child) might have a little bit of global delay but it'll be okay so I went straight back to our GP and I said, I want a new paediatrician (Rachel).

For Rachel the diagnosis and treatment for her child was further delayed by the decision to seek a second medical opinion. However, delay in accessing specialist expertise to facilitate diagnosis was common across the participants. For some children, a delay in diagnosis compounded other problems leading to further complications and additional waiting times for treatments.

It took a long time to actually get a diagnosis and because of his condition, over time, it developed into sleep apnoea and he also had trouble with periodic wind movement syndrome (Sarah)

Though the diagnosis was a long time in coming, receiving a diagnosis for their child was a significant milestone that enabled the women and their families to move forward. A diagnosis meant their child's issues were recognised and the women and their families could move forward in planning for care needs and putting these into place. Some of the mothers appeared prepared for the diagnosis and felt relief that the uncertainty had been resolved. Renee described how she felt when she got a diagnosis for her daughter at the age of four:

I cried, I felt, this is going to sound really ridiculous, I was really sad but I was relieved. I felt so just like oh ... Because I felt like it explained her behaviours. That it wasn't odd (Renee)

A definitive diagnosis enabled rural mothers to move on, as they now knew what they were dealing with. The diagnosis resolved uncertainty and validated their initial concerns about their child's health and development. However, receipt of a formal diagnosis marked the beginning of a new phase in their quest for appropriate health care that would meet the needs of their child.

\section{Prepared for the Journey}

Having to access on-going specialist health care in the city required mothers to overcome many obstacles. Advanced planning and preparation that started well before the actual appointment or hospital visit was needed, to minimise the challenges of the journey to the affected child and other family members. These challenges included arranging transport, finding appropriate accommodation, ensuring clinical letters were all up-to-date, packing medical equipment, medications, and food preparation. All of this was in addition to ensuring the family routine at home was organised and all their other maternal family responsibilities were able to be covered during their absence.

Many participants reported that their children did not manage well outside of their normal routine; and nor did the family when they were away from home. It was nearly always the mother's responsibility to reduce the impact of the disruption on the entire family. Karen discussed how she 
would organise her mother to come and stay so that the entire family was not interrupted and her husband could keep working while she was in the city for appointments.

Mum would come up and look after the kids while I was in Sydney, cos it's just too hard to take two other kids along when you're trying to sit in on doctor's appointments and things like that. There's a lot of waiting and stuff (Karen).

Despite the expense of rural and regional flights, many mothers chose to fly to reduce time away from family and work. In an attempt to reduce flight costs mothers arranged transportation as much in advance as possible. Mothers choosing to fly often had to leave home in the early hours of the morning to travel long distances to airports, catching early flights to make appointment times. Melinda, who chose to fly to appointments, explained the planning process of having to travel with her son's medical equipment:

So normally it involves a lot of administration tasks, like calling, emails, racing off to the GP to get referrals sorted. And then the packing, I've got to go to the pharmacy and make sure we're stocked up on everything we need for the trip, and then I pack our bags. Normally I start that week because we normally take a suitcase, but also a big bag of medical equipment, like a big thing that I take on the plane with his feeding tube stuff and an emergency kit in case he pulls his feeding tube out on the plane, he's got to have stuff in case he starts trying to vomit on the plane which he does. So, you've got to take all his medication and all the...So normally carrying a nappy bag, and a backpack, and a medical bag, and Flynn, and Flynn's bag, and pushing him in the pram, and then pulling a suitcase (Melinda).

Mothers' had to juggle numerous appointments with specialists including regular check-ups, followup appointments and specialist care. Kelly has two children who between them see thirteen different specialists. She travels over $500 \mathrm{~km}$ four times a year to attend these appointments. She discussed how the appointments are now coordinated through a specialist team:

Because they're all clinics, they're all out-patient clinics, and it's too far to travel just to see one specialist when we've got so many ... We have somebody down there as a coordinator ... basically specialises in rural patients coming to Sydney and she(coordinator) organises all the specialists around when we are going to be there (Kelly)

Having to attend such a high number of appointments meant many days off school affecting children's learning, social connections and school attendance records. Christine discussed balancing appointments with her daughter's school attendance: 
Ah it's those sort of things that you're constantly juggling so that you're not trying to, to clash, because she needs to be attending for her part-time attendance, or again you, you know, you've got the issue with the school saying, "We'll have to report her for non-attendance" (Christine).

Michelle, a stay at home mother of three school age children whose husband works long hours away from home, contemplated how she could escort her daughter Edwina to a specialist appointment in a metropolitan children's hospital. Michelle had little family support and so had no alternative but to take all of her children to the city for the medical appointments of her affected child. This resulted in more work for Michelle in keeping the other children amused during long hospital waits, and all children having time off school and being away from home.

I just can't figure it (care options for the other children) out and then it, the whole figuring out thing becomes such an effort, it's easier if you just come with me .... I don't have to worry and because if my husband's out of town (Michelle).

Despite all the planning and administration work required for travelling, at times there were circumstances that were unforeseeable. Accessing services away from home-required rural mothers to be flexible and responsive. Many mothers in this study discussed combining holidays and leisure activities with their city appointments as a way of justifying the large expenses, time and resources. This reduced the impact of the appointment on the entire family. As one mother stated:

And what I wasn't prepared for was that the doctor had actually said that he would not do the operation unless I would agree to stay ... within 10 minutes of the hospital for 10 days after the operation. Which ended up nice for us because we went and stayed by the beach [laughing] (Melissa).

In summary, attending specialist care in the city required rural mothers to prepare well in advance. The groundwork for organising the journey included numerous arrangements that the mothers had to manage. Consideration for overnight accommodation influenced transport modes, finances, time in disturbance to family and work routines, loss of income, time and scheduling of multiple appointments.

\section{Strangers in the city}

Participants left their communities to travel long distances to receive specialist care for their children. Many were unfamiliar with the city environment and found it both stressful and overwhelming to travel and stay in the city. Renee relied on her husband to take two days off work to drive her and their daughter to the city for an appointment: 
But when we got there it was in a suburb of the city I think, they were doing all this road work and there was, and oh it was just a nightmare, we couldn't believe it. So we actually got Sasha in there, we had headphones on her but the noise and city, and we could see her eyes like flicking (Renee).

Although catching public transport in an unfamiliar city was overwhelming for some, others were grateful as it meant they did not have to negotiate city traffic. Additionally, it allowed children to experience some aspects of city life firsthand.

In the city it's like I'll try and stay near a train station, that's one so I don't have to drive in the city because I'm not as confident as I used to be, but also because they actually love going on the trains (Melissa).

Options for accommodation included private accommodation with family members or friends, motels, hostel and on-site accommodation attached to the hospital. Accommodation choices depended on financial resources, staying in places that were familiar and comfortable, being eligible to access hospital-based accommodation and the availability of accommodation at the time. As Karen stated:

We call it our home away from home because we've been going there since Henry was a baby. And yeah, it's within walking distance of the hospital, which I like because it saves having to get Henry in and out of the car all of the time. (Karen).

Rural mothers expressed their gratitude at being able to stay in the charity accommodation attached to the hospitals, but this could also present challenges. As Kelly shared:

There's lots of cancer kids staying and that's always confronting, and it's difficult for us as well because, you know, they're immune compromised kids and our kids aren't always healthy. And so, there's always that fear that, you know, you're going to make somebody sick (Kelly).

Participants reported, that due to the cost and disruption to their families, they sometimes had to make decisions as to whether an appointment was absolutely essential or not. This decision was often related to the time it would take to get to treatment and the geographical location, the difficulty in mobilizing financial resources and support required to attend appointments in the city. Rebecca chose not to travel to the city for her child's equipment, as it was just too hard, and the impact on the family was enormous:

Ah, I just find that we just do so much travelling and, I think that, yeah, we're just at the point now where it's just another thing, you know, that we just don't have the time to travel, and we just have to wait for this appointment to come up here locally (Rebecca).

Discussion 
Within Australia, it is necessary for the primary care physicians or general practitioners (GPs) to provide a referral for specialist care, this practice refers to "gatekeeping", with the GP determining the referral of a patient to a specialist (de Vries et al., 2018). Negotiating with local gatekeepers for referrals to specialist care was difficult for rural mothers with a multitude of reasons; including health workforce shortage in rural areas, talking with multiple health care provider's, limited options and cultural differences with locums. Rural mothers described how gatekeeping led to delays in obtaining a diagnosis and treatment and increasing adverse outcomes for their child. This finding resonates with previous studies. Greenfield et.al. (2016) also found in their study that gate keeping had crucial effects on service utilisation, health outcomes, healthcare costs, and patient satisfaction (Greenfield et al., 2016).

In many areas of rural Australia there are doctor shortages. One solution to the rural doctor shortage in Australia has been for overseas-trained doctors to practice as locums. These doctors generally provide coverage in communities for three to six months (Han and Humphreys, 2005). Hence, continuity of care can be disrupted, and mothers need to keep retelling the story of their child's condition in order to get a diagnosis, referral for specialised services and access to appropriate ongoing care.

Access to specialist's medical practitioners contributed to further delay for rural mothers seeking a second opinion and diagnosis. Within Australia, medical specialists tend to divide their time between public hospital inpatients, private rooms, private hospitals, public hospital outpatient settings making waiting list longer due to their divided and often limited time for appointments (Health and Welfare, 2016). Like general practitioner there are fewer medical specialist practicing full time in rural areas, instead there are a few medical specialist who travel to rural areas to provide outreach services resulting in limited availability and long waiting times for rural residents (Health and Welfare, 2016; O'Sullivan et al., 2017; Hussain and Tait, 2015). Medical workforce in Australia including both general practitioners, medical specialist are geographical distributed along coastal areas of Australia with fewer doctors in regional, rural and remote areas of Australia compared to capital cities (Australia, 2012)

Rural mothers and their children with chronic health conditions travelled substantial distances to access healthcare and support services for their children. Rural GPs, like their metropolitan counterparts, are reliant on secondary or tertiary paediatricians to provide care for children with chronic health conditions, making travel a necessary part of care (Turbitt et al., 2017). In previous studies, rural residents with complex diseases, disabilities and/or injury experienced greater difficulties accessing health care services for numerous reasons including; lack of local specialist health 
care and services, long waiting lists, and by-pass local care and services (Glennie et al., 2017; Goodridge et al., 2015; Dew et al., 2016; Vindrola-Padros et al., 2018). Distance is a known major barrier to accessing health care treatment (McGrath, 2015b); however, for rural mothers in this study this barrier was just another hurdle in the care for their child.

Travelling to the city for health care had a substantial economic impact on individuals and carers. Previous studies on rural patient's needing to travel for cancer treatment revealed similar experiences to those of the rural mother in this study (Aitken and Hathaway, 1993);(Clavarino et al., 2002); McGrath, 1998, 2001a; Wilkes et al., 2006). For rural mothers in this study, travelling long distances to the cities for health care disrupted their daily lives producing extras stressors. Their children often did not manage well outside of their normal routine (Ashburner et al., 2016; Clavarino et al., 2002). Other stressors included additional expenses for telephone calls, parking, laundry, pharmaceutical products, and associated accommodation costs, and meals, all in addition to maintaining their usual household. Although expenses are reimbursed through a government scheme the full financial cost is not recovered. Travelling to the cities caused both anxiety and fear for many as they anticipated the travel, changes in their routine, leaving family at home and financial hardship, similar to findings reported elsewhere (McGrath, 2015a; McGrath, 2015c; Dew et al., 2013; Gallego et al., 2017). In addition to this, mothers in this study expressed distress being in the city environment as it was foreign to them; in particular, the noise, driving on unfamiliar roads and navigating traffic congestion, parking, crowds and public transport.

Rural mothers described the preparation required for being away from home to attend their treatment and appointments as arduous; an issue also identified by other studies (Wagland et al., 2015). Having to organise multiple appointments, accommodation, travel arrangements, travel bookings, packing medical supplies, and meal preparation prior to travelling all contributed to high levels of stress and disruption to family life making the journey much more difficult (Wagland et al., 2015; Bettencourt et al., 2007; Clavarino et al., 2002).

In this study, the rural mothers identified as the primary carer for their child with a chronic health condition requiring them to negotiate a complex health care system across vast distances to ensure their child received the treatment and services they required. Rural mothers had to exchange and share information between multiple service types and health care providers (McPhail, 2016). This process was frustrating and challenging, making care coordination difficult.

Recommendations - Having a principal care coordinator within their rural community could assist in providing easier transitions and communication as mothers discussed the care of their child to was often disjointed because of the number of health providers involved and their location (McMurray 
and Cooper, 2017; Hudson et al., 2019; Pesut et al., 2017). A rural nursing care coordinator could assist in providing communication between local and specialist health providers coordinate travel and accommodation requirements and build relationship between clinicians and service providers to support them in providing care children with $\mathrm{CHC}$ locally. This could be done through the use of telehealth with, shared electronic health records between private and public health providers and state and federal health care systems.

Conclusion -This paper provides evidence that rural mothers experience significant challenges in accessing the care requirements for their child with a $\mathrm{CHC}$. The findings provide valuable, in-depth insights into rural mother's own experiences of accessing services outside of their own community and the practicalities of travelling and being away from home posed on them. Rural mothers had to learn how to overcome these barriers to ensure their child received the care requirements they needed despite their rural location. The major barriers identified involved issues with early diagnoses, referral processes, accessing care outside what is familiar to them and communication. Our findings illustrate the need for further support for rural mothers to ensure their child has access to health-care and service requirements. For rural residents' geographical distances, financial resources, workforce shortage and communication breakdown limit access to health care. Providing a central source for communication, coordination and collaboration will assist in reducing these access barriers to achieve health equality for rural children with $\mathrm{CHC}$. With increasing number of children with chronic health conditions globally, it is important that services are responsive to a child's care needs in order to promote and maintain health, regardless of their geographical location, to assist in reducing avoidable disability and premature death.

Limitations - The rural mothers in this study all volunteered to be interviewed and were proactive in their child's care and it is important to remember that the experience of mothers who did not volunteer to participate may not be similar. Furthermore, all participants were members of the dominant white culture, all were in partnered relationships and none were affected by extreme poverty. It is likely that Indigenous mothers, single mothers, and women mothering in the context of extreme poverty may face additional challenges. Future studies should attempt to increase diversity and it may be that other recruitment strategies would be useful in achieving this. Data were collected during intense drought conditions which meant that participants, their families and communities were under increased and continuing financial and emotional stress. 
Aitken TJ and Hathaway G. (1993) Long distance related stressors and coping behaviors in parents of children with cancer. Journal of Pediatric Oncology Nursing 10: 3-12.

Ashburner J, Vickerstaff S, Beetge J, et al. (2016) Remote versus face-to-face delivery of early intervention programs for children with autism spectrum disorders: Perceptions of rural families and service providers. Research in Autism Spectrum Disorders 23: 1-14.

Australia HW. (2012) Health Workforce 2025-Volume 3-Medical Specialties.

Barlow JH and Ellard DR. (2006) The psychosocial well-being of children with chronic disease, their parents and siblings: an overview of the research evidence base. Child: Care, Health and Development 32: 19-31.

Berntsson L, Berg M, Brydolf M, et al. (2007) Adolescents' experiences of well-being when living with a long-term illness or disability. Scandinavian Journal of Caring Sciences 21: 419-425.

Bessette Gorlin J, McAlpine CP, Garwick A, et al. (2016) Severe Childhood Autism: The Family Lived Experience. J Pediatr Nurs 31: 580-597.

Bettencourt LMA, Lobo J, Helbing D, et al. (2007) Growth, innovation, scaling, and the pace of life in cities. Proceedings of the National Academy of Sciences 104: 7301-7306.

Bristow S, Jackson D, Shields L, et al. (2018) The rural mother's experience of caring for a child with a chronic health condition: An integrative review. Journal of clinical nursing 27: 2558-2568.

Buran CF, Sawin K, Grayson P, et al. (2009) Family needs assessment in cerebral palsy clinic. Journal for Specialists in pediatric Nursing 14: 86-93.

Clavarino AM, Lowe JB, Carmont SA, et al. (2002) The needs of cancer patients and their families from rural and remote areas of Queensland. Australian Journal of Rural Health 10: 188-195.

Cousino MK and Hazen RA. (2013) Parenting stress among caregivers of children with chronic illness: a systematic review. Journal of pediatric psychology 38: 809-828.

de Vries E, Fransen L, van den Aker M, et al. (2018) Preventing gatekeeping delays in the diagnosis of rare diseases. Br J Gen Pract 68: 145-146.

Dew A, Bulkeley K, Veitch C, et al. (2013) Carer and service providers' experiences of individual funding models for children with a disability in rural and remote areas. Health \& Social Care in the Community 21: 432-441.

Dew K, Scott A and Kirkman A. (2016) Health Consumers and the Clinical Encounter. Social, Political and Cultural Dimensions of Health. Springer, 7-22.

Farmer JE, Clark MJ, Sherman A, et al. (2005) Comprehensive Primary Care for Children With Special Health Care Needs in Rural Areas. Pediatrics 116: 649-656.

Flood A. (2010) Understanding phenomenology. Nurse researcher 17.

Gallego G, Chedid R, Dew A, et al. (2016) Private practice disability therapy workforce in rural New South Wales, Australia. Journal of allied health 45: 225-229.

Gallego G, Dew A, Lincoln M, et al. (2017) Access to therapy services for people with disability in rural A ustralia: a carers' perspective. Health \& Social Care in the Community 25: 1000-1010.

Glennie RA, Batke J, Fallah N, et al. (2017) Rural and urban living in persons with spinal cord injury and comparing environmental barriers, their health, and quality-of-life outcomes. Journal of neurotrauma 34: 2877-2882.

Goodridge D, Rogers M, Klassen L, et al. (2015) Access to health and support services: perspectives of people living with a long-term traumatic spinal cord injury in rural and urban areas. Disability and rehabilitation 37: 1401-1410.

Greenfield G, Foley K and Majeed A. (2016) Rethinking primary care's gatekeeper role. Bmj 354: i4803.

Han G-S and Humphreys JS. (2005) Overseas-trained doctors in Australia: Community integration and their intention to stay in a rural community. Australian Journal of Rural Health 13: 236-241.

Health Alo. (2012a) Australia's Health 2012: The Thirteenth Biennial Health Report of the Australian Institute of Health and Welfare: AlHW.

Health Alo. (2012b) A picture of Australia's children 2012: AlHW. 
Health Alo and Welfare. (2016) Medical practitioners workforce 2015. Canberra: AlHW.

Hoogsteen L and Woodgate RL. (2013) The Lived Experience of Parenting a Child With Autism in a Rural Area: Making the Invisible, Visible. Pediatric Nursing 39: 233-237.

Hudson AP, Spooner AJ, Booth N, et al. (2019) Qualitative insights of patients and carers under the care of nurse navigators. Collegian 26: 110-117.

Hussain R and Tait K. (2015) Parental perceptions of information needs and service provision for children with developmental disabilities in rural Australia. Disability and rehabilitation 37: 1609-1616.

Jackson D and Mannix J. (2004) Giving voice to the burden of blame: A feminist study of mothers' experiences of mother blaming. International Journal of Nursing Practice 10: 150-158.

Lauver LS. (2010) The lived experience of foster parents of children with special needs living in rural areas. J Pediatr Nurs 25: 289-298.

Leeman J, Crandell JL, Lee A, et al. (2016) Family Functioning and the Well-Being of Children With Chronic Conditions: A Meta-Analysis. Research in Nursing \& Health 39: 229-243.

McGrath P. (2015a) Parking problems: An important access issue for Australian specialist metropolitan hospitals. Health Issues: 26.

McGrath P. (2015b) Technology-based patient consultations: research findings from haematology patients in regional, rural and remote Queensland. The Patient-Patient-Centered Outcomes Research 8: 199-206.

McGrath P. (2015c) 'You never leave work when you live on a cattle property': Special problems for rural property owners who have to relocate for specialist treatment. Australian Journal of Rural Health 23: 286-290.

McMurray A and Cooper H. (2017) The nurse navigator: An evolving model of care. Collegian 24: 205212.

McPhail SM. (2016) Multimorbidity in chronic disease: impact on health care resources and costs. Risk management and healthcare policy 9: 143.

Murphy KL, Kobayashi D, Golden SL, et al. (2012) Rural and nonrural differences in providing care for children with complex chronic conditions. Clinical Pediatrics 51: 498-503.

Nygård C and Clancy A. (2018) Unsung heroes, flying blind-A metasynthesis of parents' experiences of caring for children with special health-care needs at home. Journal of clinical nursing 27: 3179-3196.

O'Sullivan BG, McGrail MR and Stoelwinder JU. (2017) Reasons why specialist doctors undertake rural outreach services: an Australian cross-sectional study. Human Resources for Health 15: 3.

Pesut B, Hooper B, Jacobsen M, et al. (2017) Nurse-led navigation to provide early palliative care in rural areas: a pilot study. BMC palliative care 16: 37 .

Sen Gupta T, Reeve C, Larkins S, et al. (2018) Producing a general practice workforce. Australian journal of general practice 47: 514.

Skinner AC and Slifkin RT. (2007) Rural/Urban Differences in Barriers to and Burden of Care for Children With Special Health Care Needs. The Journal of Rural Health 23: 150-157.

Sodi T and Kgopa B. (2016) Coping strategies of mother carers of children living with chronic illness and disease in a rural South African community. Journal of Psychology in Africa 26: 432-435.

Swallow V, Macfadyen A, Santacroce SJ, et al. (2012) Fathers' contributions to the management of their child's long-term medical condition: a narrative review of the literature. Health Expect 15: 157-175.

Tong A, Jones J, Speerin R, et al. (2013) Consumer perspectives on pediatric rheumatology care and service delivery: A qualitative study. Journal of Clinical Rheumatology 19.

Tong A, Sainsbury P and Craig J. (2007) Consolidated criteria for reporting qualitative research (COREQ): a 32-item checklist for interviews and focus groups. International journal for quality in health care 19: 349-357.

Turbitt E, Kunin M, Gafforini S, et al. (2017) Perspectives of Australian general practitioners on shared care for paediatric patients. Australian Journal of Primary Health 23: 147-153. 
Van Manen M. (1990) Researching Lived Experience: Human Science for an Action Sensitive Pedagogy (London, Ontario. The Althouse Press.

Van Manen M. (2001) Professional practice and 'doing phenomenology'. Handbook of phenomenology and medicine. Springer, 457-474.

Vindrola-Padros C, Brage E and Chambers P. (2018) On the road and away from home: a systematic review of the travel experiences of cancer patients and their families. Supportive Care in Cancer: 1-10.

Wagland K, Levesque JV and Connors J. (2015) Disease isolation: The challenges faced by mothers living with multiple myeloma in rural and regional Australia. European Journal of Oncology Nursing 19: 148-153. 